LA-UR-93- 1816

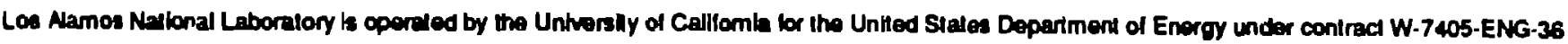

\title{
TITLE: Design For Low Beam Loss In Accelerators for Intense Neutron Source Appllcations
}

AUTHOR(S): A. A. Jameson

$$
\text { Jivis } 04 \text { : }
$$

\begin{abstract}
DISCLAIMER
This report was prepared us an hecount of work sponsored by un agency of the United States (iovernenent. Neither the United Stutes (jovernment nor any agency thersor, nor any of their employeen, makes any warrunty, express or implied, or assumes any legul liubility or respontibility for the accuracy, completenem, or urefulness of any information, upparatus, puoduct, or proxess disclomed, or represents that its use would not infringe privately owned righls. Keference herein to any specific commercial product, process, or service hy Irade nanic, Irademark, manufuclurer, or otherwise doen not necessurily conslitute or imply its endorsement. recommendation, or Favoring by the I/nited Sintes (iovernment or any agency thereof. The views und opinions of wuthors expressed herein do not necessurily stute or reflect thoue of the Inited Sintes (iwvernment or nny ugency thereor.
\end{abstract}

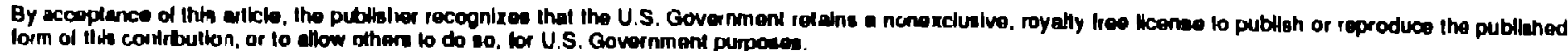

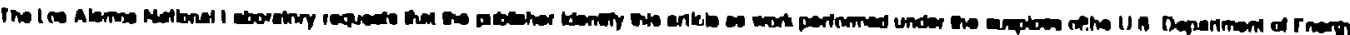

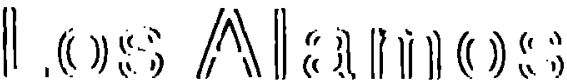

Los Alamos National I. aboralory

L.os Alamos, Naw Moxtco 87:545

ropm No. ase FA

sT NO $25205 / 01$

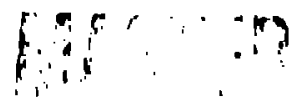




\title{
Design for Low Beam Loss in Accelerators for Intense Neutron Source Applications
}

\author{
Robern A. Jameson \\ Accelerator Technology Division \\ Los Alamos National Laboratory, Los Alamos, NM 87545
}

\begin{abstract}
Control of beam loss in intense ion linacs involves keeping beam spill below parts in $10^{-5}-10^{-8} / \mathrm{m}$ by preventing total beam size from extending to the limiting apertures. Starting from gond rms design practices, new analysis of the machine architecture is described in terms of the effects of the machine tune with space-charge, free-energy constraint, and haloproducing mechanisms. It is shown that halos are produced by the time- (or position-) varying nature of common linac aspects (such as misalignment, mismatchir,g, acceleration, and construction techniques) through collective core/sirgleparticle interaction dynamics plus resonances.
\end{abstract}

\section{INTRODUCTION}

High-intensity neutron sources can provide solutions to society's requirements for defense and commercial radioactive actinide and fission-product waste disposal and gencration of electric power without a long-term waste stream [1-2], a pulsed neutron research facility [3], production of tritium and other special materials [4], conversion of plutonium, and the development of advanced materials [5]. These neutron sources are driven by large linear accelerators, with 30-300 $\mathrm{mA}$ proton current at energies of $1-2 \mathrm{GeV}$ and $10-100 \%$ duty factors for the applications in [1-4], and modules of up to 250 in $\mathrm{A} \mathrm{cw}$ deuteron current at $40 \mathrm{MeV}$ for the materials development program.

These accelerators would have $u_{2}$ to a few hundred megawatts of beam power, a large factor above the $\sim \mathrm{MW}$ capability presently available at LAMPF. However, the power extrapolation is not fundamentally difficult; a factor of - 44 would be realized if LAMPF ran $\mathrm{cw}$ and all the of buckets were filled. The major challenge is to kecp residual activation of the linac by stray beam loss low enough that remote manipulator maintenance is not required; i.e., average losses should not exceed present L.AMPF levels, translating to a ruleof thumb of $<1 \mathrm{nA} / \mathrm{GcV} / \mathrm{m}$. Dealing witu more particles per tunch is the main challenge of the extrapolation. Most of the proposed configurations require within 2-3 times more particles per bunch, with the maximum scenario at 4.5 . Acceleration of peak currents of these magnitudes has been achieved, but attainment of the required low loss most be (':monstrated

Typwally, in real linacs and in multiparticle simulations of them, a high-intersity bean will develon a diffuse outer "halk" that can contain as much as a few pereent of the leam current. If this halo extends to the tere radius, particles wiit be scrapes off. There is presently no analytical guidance to perfomance at such low levels, and the physics in the sumulation lools is also not accurate enrugh. Present design practice 13 . 51 concentuates on comtrolling the transverse and longitudinal rms heam sizes in ways that insure maximum "aprerture factors" (or salk stay-rlear ratios of tere-10-rms. beam fadlius and accelerating bucket-10-me leam leng!h) wilhin various construints. Reference design work for the ex: w applications avoids abrupt transitions such as those that cause "hot spots" at LAMPF, and achieves rms aperture factors from 2-3 times larger than the LAMPF design. New designs, including an anticipated error budget, are checked by simulation with up to a few hundred thousand particles, and is judged satisfactory if no particles are observed to hit the bore.

The simulations do show growth of the rotal beam size. The intent of this paper is to discuss aspects of total beam size. the corttrol of which is the true goal of loss minimization.

\section{ARCHITECTURE OF PRESENT DESIGNS}

Two dominant features characterize the essentials of a typical RFQ accelerating section, a DTL, or a long coupledcavity high-beta ion linac (CCL). Typically the accelerating gradient is held constant, because of $\mathrm{rf}$ power cest or sparking constraints. This results in rather small longitudinal focusing that decreases with energy, so the longitudinal zero-current phase advance per period decreases. The longitudinal tune depression from the beam space-charge then stays about constant with energy, typically -0.4 , a value at which the space-chargz and cmitiance have approximately equal effect. There is phase damping with acceleration and the beam rms phase width shrinks, resulting in a larger rms longitudinal aperture factor [6].

Sirong transverse focusing is relatively casy to obtain. With constant transverse focusing per unit length, the external focusing effect increases with encrgy as the space-charge forces weaken. The rms beam size shrinks, increasing the rms transverse aperture factor. The transverse tune depression, which may bx sil (n) $(-10.4)$ at low energy, rapidly weakens.

In terms of the plasma period of the heam, the $1-2$ GeV linas is long .... of order 100 plasma periods.

The emittance and aperture factor behavior reflect the architecture, as shown in Fiy. I for a typical $140 \mathrm{m.l}, 20-1.5(\mathrm{x})$ $\mathrm{McV}$ proton linac. In this typical simulation, the crror-free linac is smoothly varying and the input beam is a mathematical, clean-edged distribution injected on-ax is and rmis-matched.

The tune trajectorics are ploted on Hofmann's beam instability chart 171 , Fig. 2, 10 check whether he observed growth can be explained in this way. The lon adlinal/(rans. verse rms emiltance ratio stays at -.2 . At $20 \mathrm{McV}$, the trajectories are initially below the 4h-even mode thresholds and a rapid cquilibration oceurs in $1 / 4$ plasma perool $(-1-2$ tanks). The passage through the Brd-odd region is fast, without evident effect on: the rms emitlance, and then the transverse tune is alove the thresholds. So the lower order Hofmann mokles do not explain the growth. Pafure wonk may ix able wo invoke the higher order modes as an explanation, perhaps in conjunction with the halon physics In Ix presented in Scction III.

It is clear from t.ip. 2 that the transverse/longiludinal concrgy halance (or pantitioning) is nor cejual through mest of 


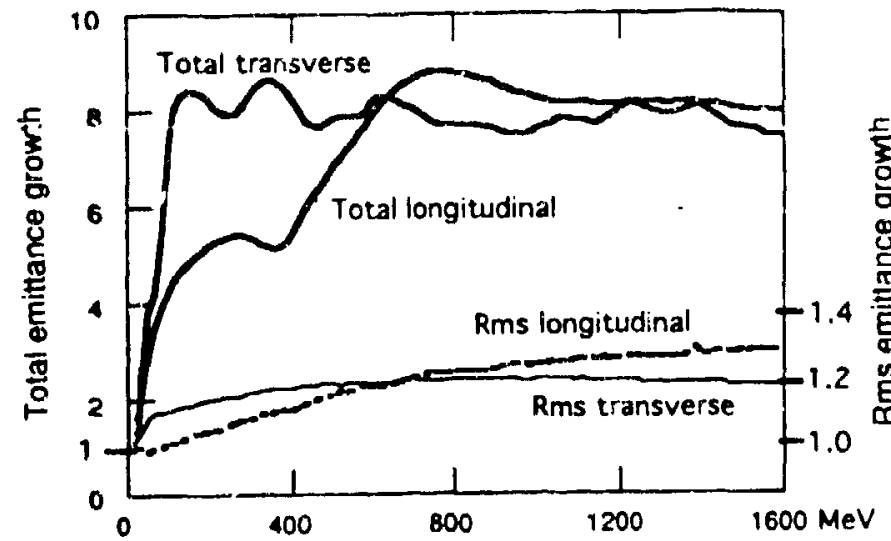

Fig. 1.a. Emittance growth in a typical CCL.

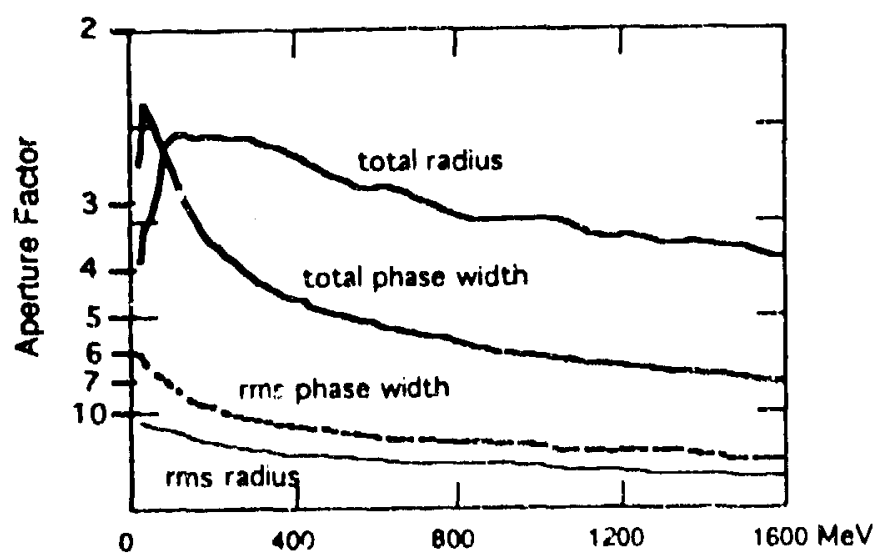

Fig. 1.b. Aperture factors in a typical CCL.

the linac $[8,9]$ and thus free energy is available that can be convertad via nonlinear processes to size/emiftance growth. A major phase of present research now in progress is to modify the machine tune so that various degrees of ecquipartitioning can be studied. Because the architecture ceonomics specified the longitudinal tunc, cyuipartitioning means a decrease in the transverse f(xusing with cnergy. Growth in rms bearn size (perhaps a factor of 3.4) will occur along the makhine, but if cotal beam size growth is reduced, an overnll improvenent may result. This work requires a self-consistent simulation cole $[8,9]$, which is being ujolated. 'These future studies of benm involved machine lunes may resull in a hybrid tune. with better enesgy balance at low energies where spaxe-charge is more dominant, and stronger focusing at higher cnergies.

Using the: rons matching cquations and the c(quijartitioning relationship, scaling and optinization cyuations for the aperture factors can be formulated (6). Unfortunately, they are highly coupled and nonlinear and thus are not solvable except under special circumstances, such as constart eyuipartitioning ratios. In that case, lhe sperture finclors are niways larger ill lower lienuency. In olluer cases, optimum frequenu ies are evidenced in numerical stullies, and sone very strong relationshipes ne indicated, such as that the me rimum aperture factor always occurs it an almost constame lume depression. Some asjects of liese kernel relitionships have been dascovered. hitt the ir hasic forms remain elasive.

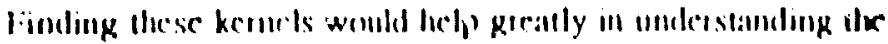

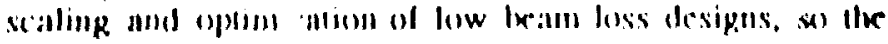
scarch comlinues.
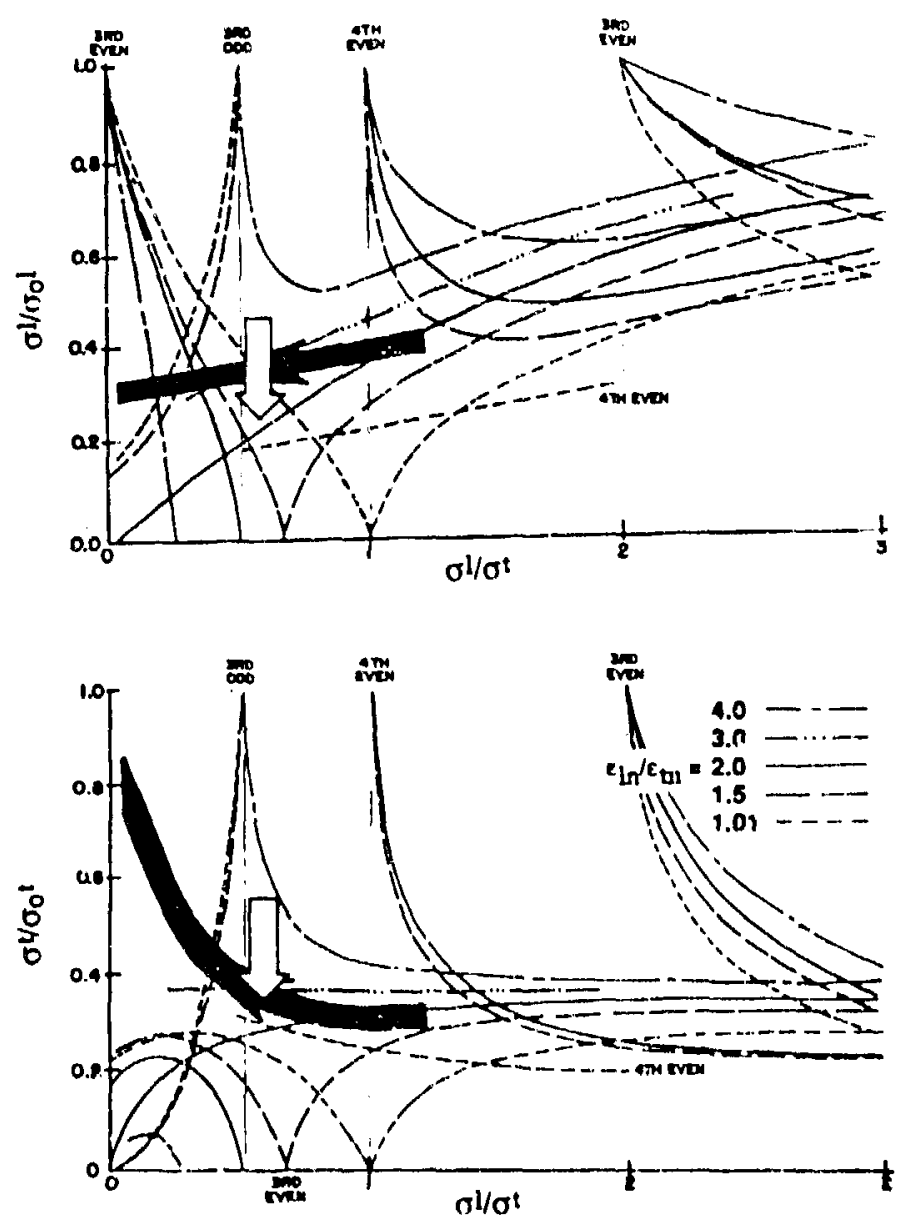

Fig. 2. (Cl. tune trajectories on Hofmann mstability chart. Typical 140 mA. 20-15(0) MeV (C.C. (black arrows), and equipartitioned tunc (white arrows).

\section{PIYYSICS OF HIALO BEAMS}

Preventing halo formation a priori is the point-of-vicw of the research thrusts of this paper. We know that this means kecping nonlincaritics sinall in both the external fields and in the beam space charge, kecping the heam well matched, well aligned, and energy balaneed, as much ns ponsible within the many constraints. The latter make it hart: for examble. strict equipartitioning is difficule lo achicve practically, especially with the necd of change axceleratex structure and use a bigher harmonic of at highes energy. Thus we do have to sa arch for the mechanisens causing halo formation and how they alfecl nllownble ermor budgets.

The lower order llofmann insubility modes did not explain the results in this case. (Mher analyses $(10-12)$ have related montinear fielel energy and diffusion to arymyentic rms prowfh (from errors of energy imbalance, misuligument, rms mismatch, and inpur distrihution mismatch) in transpunt systems, bus these ne mot easy (1) apply (1) an ancelesalom, asul

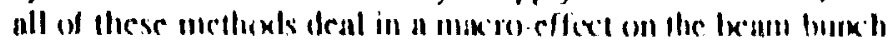
thit dexes not reveal what really haperens to particles that may form a halo. It had long lecen obsectucal than pancicles

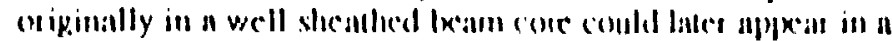

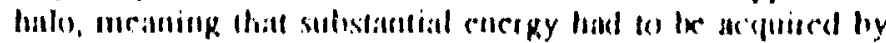
than patticle, hut lle mechanism was not kmewn. Thete were 
many questions - are halos generated continuously; will they reappear if scraped; why do different error conditions produce different halo effects?

Substantial new insight has been obtained by looking at detailed single-paricle behavior in computer experiments [13]. The key mechanisin is very simple, and the phenomenology is elucidated in the experiments described below. Development of the corresponding theory and analytical relation to machine tolerances is now required, and should procecd rapidly. As indicated schematically in Fig. 3,

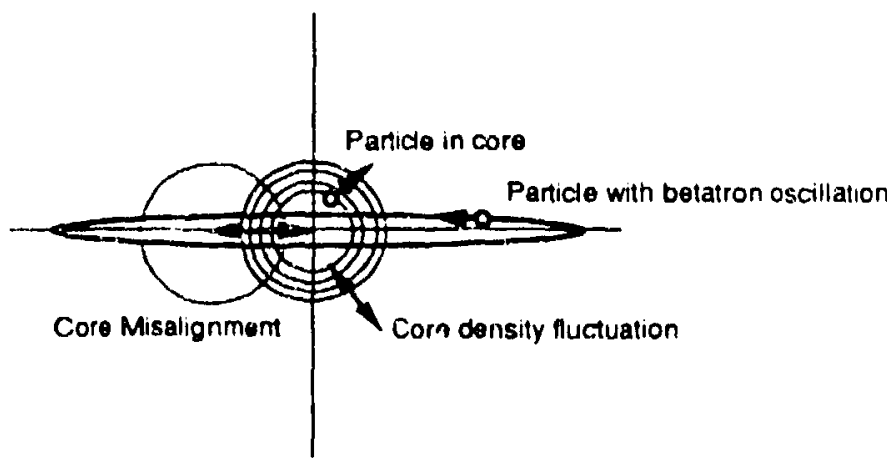

Fig. 3. Sihematic of collective core/single-particle haloproducing mochanism.

the collective interaction of single particles with the beam core, when a density change in the core or a relative motion between the particle and the core occurs within an appropriate lime, is a major halo-proxlucing mechanism. Large encrgy transfers can occur in a single interaction; e.g., a particle with initial betatron motion can le slowed, stopped, reversed, or be accelerated by a "slingshot" effect amalogous to a spacearaft passing a boxly in space. A particle initially at rest inside the core can receive a strong push from a nearby density fluctuation. The accelerator is an essentially periodic system, so core fluctuations that are excited will oscillate periodically, and when a single-particle tune moves into resonance with the core oscillation, resonant interactions result in large orbits. Thus can particles move from the center of the core into the outer halo. The resonances tend to self-limit as the particle tune changes when its orbit changes. The core/single-paricle interactions give a unifying insight into the halo-forming contributions of mismatching. misalignment, energy unbalance, altemating-gradient focusing, constant-beta linac sections, bunching, acceleration and other causes of beam core nuctuation. Some of the features of the mechanism are brichy summarized in the following.

The time-varying dynamics were first understood by observing the behavior of an inivially round, continuous, zeroemittance, strongly mismatched, 3- $\sigma$ Gaussian beam launched into a linear continuous radial fucusing channel. Fig. 4 shows its evolution. (When $x$ or $y$ change sign, the sign of $r$ is reversed, and $r^{\prime}$ adjusted, to aid the eye.) At $z / w p=0.375$ plasma periods, some particles are still at rest near the origin. Then the outer tail sweeps through the origin, causing a local density anomaly there that repels nearby paricles, and also slows or speeds up particles in the tail. This can be observed at $z / w p=0.5$ and subsequently. Repeated interactions of this type result in folding of segments into a beam core ( $z / w p=3.875)$, from which new tail segments begin to emerge. By $z / w p=9.750$, the new tail extends almust as far as the original tail. The result of an abrupt scraping of the halo at $z / w p=50$ cail now he easily anticipated by considering the mechanism as described above - a strong central density oscillation is still present, so halo continues to form.

Fig. 5 shows the central density fuctuation induced by launching a warm (initial tune depression -0.4) mismatched Gaussian beam, and the ar' radius of the six particles (from a se: of $10 \mathrm{~K}$ ) that had the largest $\mathrm{rr}^{\prime}$ radii at $\mathrm{z} / \mathrm{wp}=10$. The sharp dip in $\pi$ ' indicales a passige throngh the core, and it
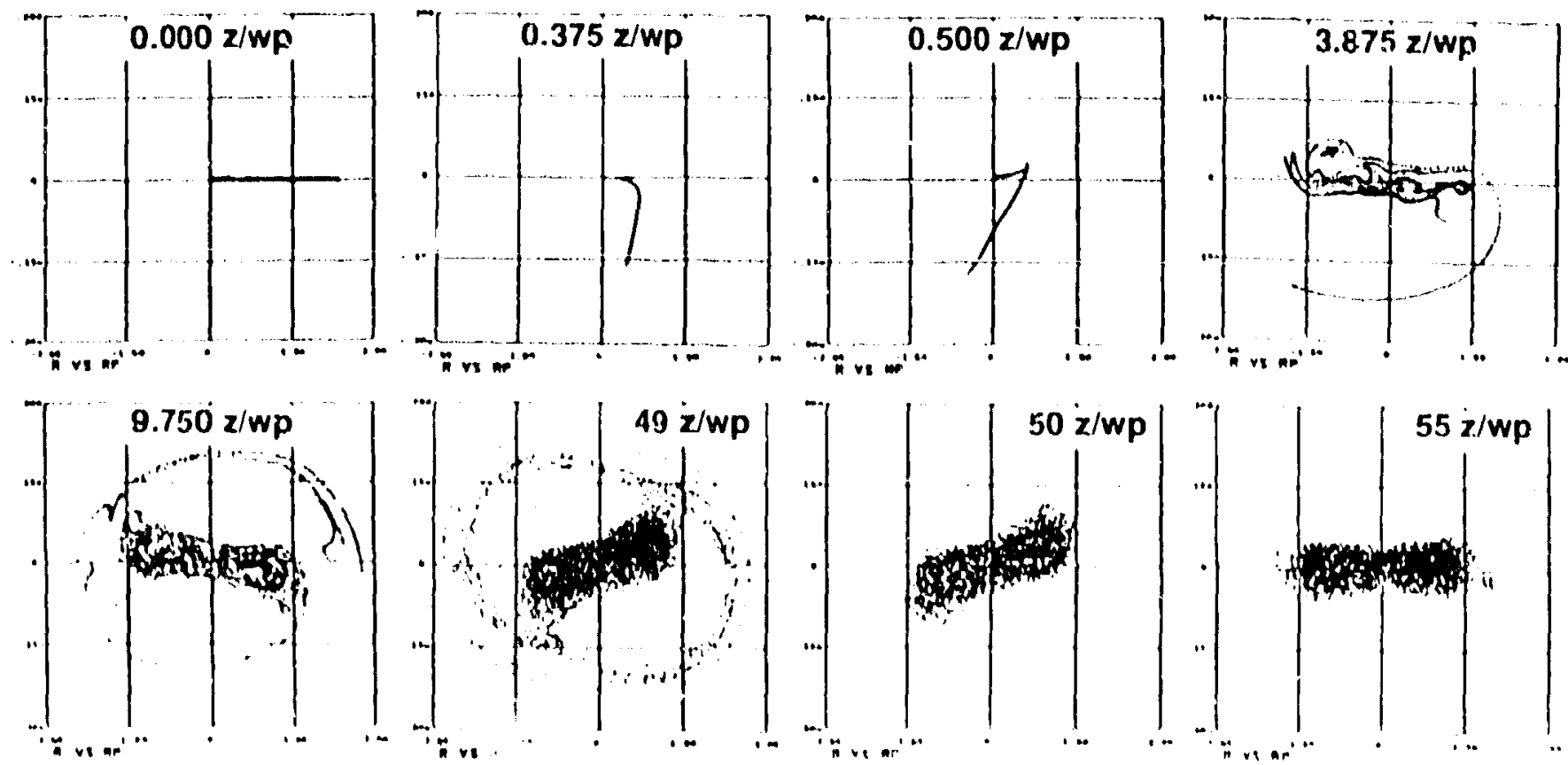

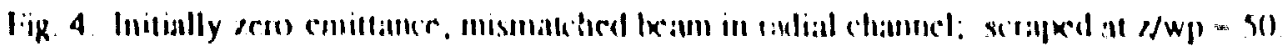


will be noted that the peak in $\pi$ ' following each of the se interactions with the core is larger (if the interaction occurred when the central density was rising), or smaller (if the central density was falling). There is a resonant buildup during the first 5 inieractions, with a change in single-particle tune that causes a slip to the fa!ling density phase, resulting in loss of energy and chunge of tune back into resonant growth again at the and.

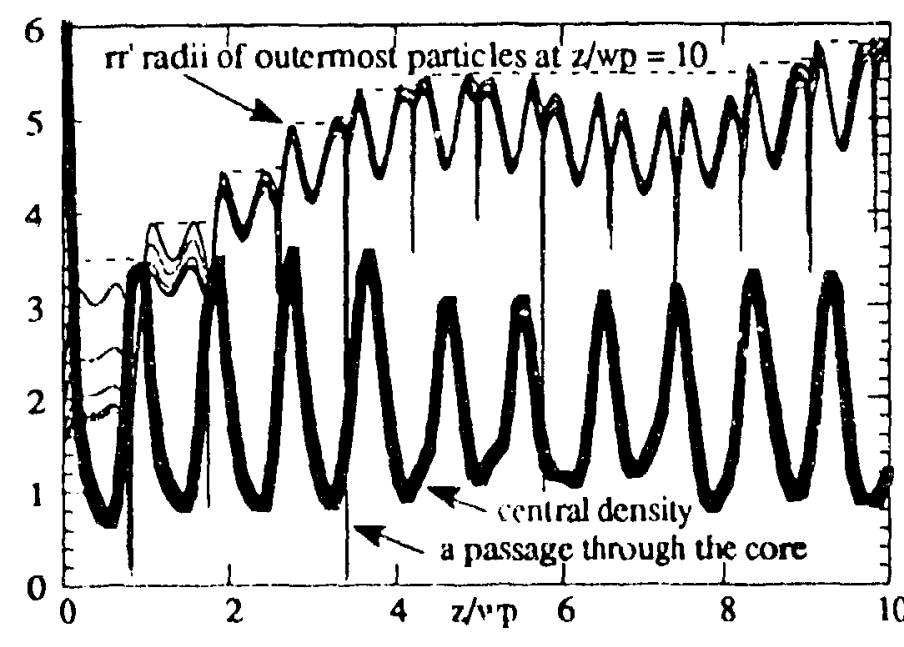

Fig. 5. Warm nismatched heam in radial channel

St:uionary distributions can be formed [14] for the timeindependent continuous radial focusing system using functions of the single-particle Hamilonian (including space-
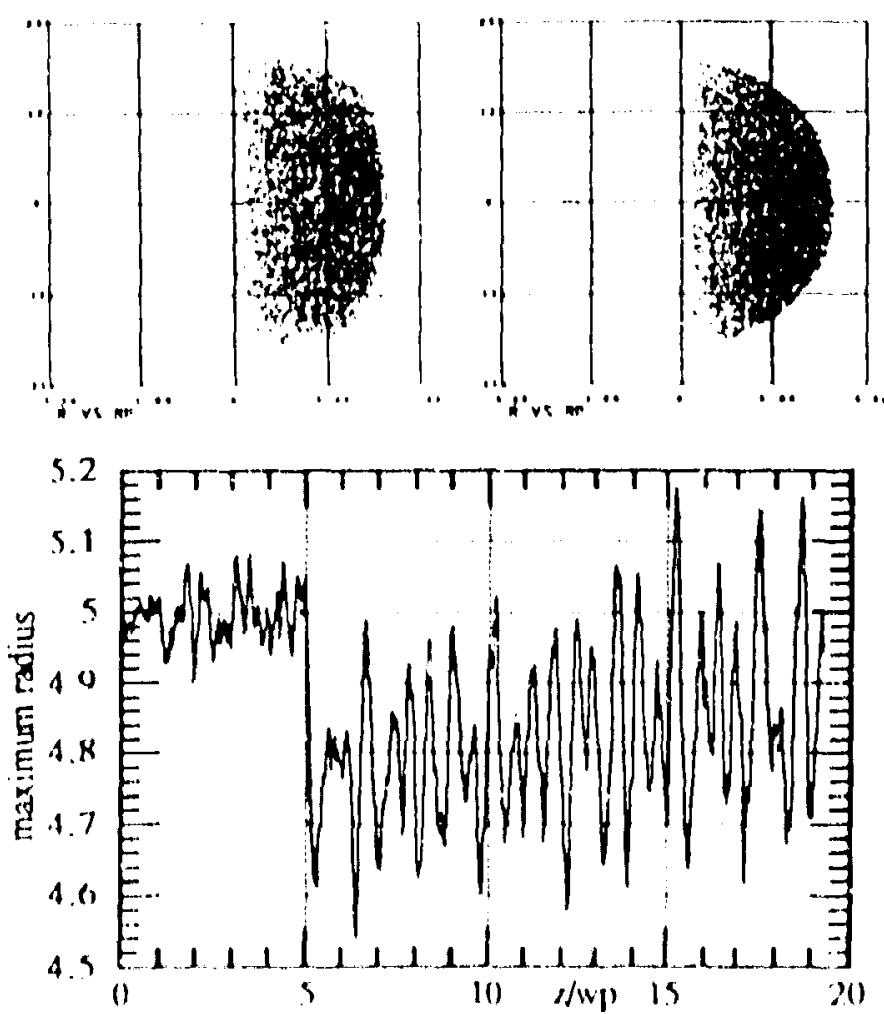

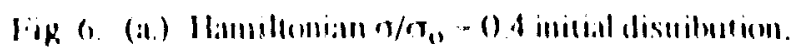

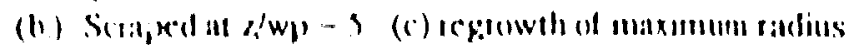

charge). The beam radius and focusing strength are chosen, giving the tuis depression. In $r-r$ ' phase space, the distribution has a squarish shape that sharpens with more tune depression (Fig. 6.a.) An initial distribution with tune shift $\sigma / \sigma_{0}=0.4$ was scraped with an elliptical $\pi^{\prime}$ filter after 5 plasma periods (Fig. 6.b.). This excited a central density oscillation, and the maximum beam radius grew back larger than the initial value (Fig. 6.c.). As expected, the largest radius particles were driven as described above.

The stationary $\sigma / \sigma_{0}=0.4$ distribution was given an initial mismatch of 1.5 in radius. After 20 plasma periods, rms emittance had grown only $2-3 \%$, the maximum rms radius remained unchanged, but the maximum radius grew by a

factor of -2.4 (times the matched radius - includes all the mismatch) via a strong resonant interaction on the rising side of the central density Juring the period from $8-14 \mathrm{z} / \mathrm{wp}$.

With an initial $50 \%$ beam radius misalignment (in $\mathrm{x}$ ) of the $\sigma / \sigma_{0}=0.4$ Hamiltonian distribution, the rms emiltance oscillated to a peak of $-15 \%$ growth, damping to $3-4 \%$ at 10 $2 / w p$. The maximum radius grew about $5 \%$ beyond the shift introduced by the misalignment. Only a small oscillation was excited in the centual density over this distance. There was about $20 \%$ damping of the $x$-centroid oscillation, with giowth in the $y$-centroid motion. The reason for the small total growth is that theie is no resonant effect because of the wide separation between the particle tunes (near 0.4) and the undepressed betation motion of the beam centroid. We would then expect more disturbance to a beam with less tune depression, and this was indeed the case. A $50 \% x$ misalignment of a $\sigma / \sigma_{0}=0.83$ distribution resulted in $12 \%$ ms emittance growth over the first $6 \mathrm{k} / \mathrm{wp}$. The inaximum bcam radius grew $20 \%$ beyond the misalignment shift (or 10 1.8 times, including the misalignment, the radius of the onaxis beam). The $x$-centmid oscillation (Fig. 7) dimped about a faxtor of 10, with excitation of a central density oscillation during the strongest part of the centroid oscillation damping. that then continued at roughly constant amplitude and a frequency slightly higher thatl that of the decaying centroid oscillation. Fig. 7 also shows the $r^{\prime}$ radius of the particle that was largest at $/ / w p=10$. achicved by resonating with the $\sigma_{0}$ position-oscillation of the rising alge of abs $\left(x_{\text {mean }}\right)$ during the first $6 \mathrm{x} / \mathrm{wp}$. From $6-15 \mathrm{z} / \mathrm{wp}$, the particle's rr' radius decreases as it interacts with the ndmixture of centroid and central density oscillations. From $1.5-20 \mathrm{z} / \mathrm{wp}$, the centroid oscillation is smail and the particie moves out again in resonance with the rising elge of the central density oscillation. This evitlence that misaligument effects are worse for a beam with small tune depression is another teasun to explexe the cepuipartitioned ture of Fig. 2

Fancrgy ceptilibration via cquipartitioning was demonstraticed by injecting an unbalanced leam using the $\mathrm{xx}^{\prime}$ dist: ibution from a $\sigma / \sigma_{0}=0.1$, and yy from a $\sigma / \sigma_{0}=0.83$ distribution. In

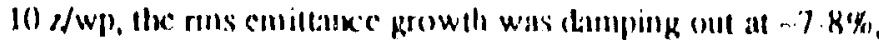
but the maximum radius growll, was aboun $25 \%$ and still prowing almose lineanly. A stong contral de aty oseillation was exciled, wilh an increase in maximum ia 'ws on cevery rise in contral density.

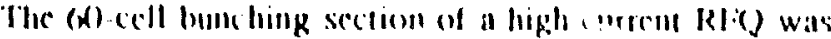
also studked |1 | In this section, the |xam is att injertion cherky and encounters a steadily rising bum-hing voltage. The fomming bunch makes a tunc dependent de asity distribution. 
A few (order $0.2 \%$ ) particles werc anomalously repelied longitudinally far from the bunch point, in some cases into the next bucket. It was found that these extraordinary orbits were strongly corrclated with very close encounters with the transverse $x x$ ' $y y$ ' origin.

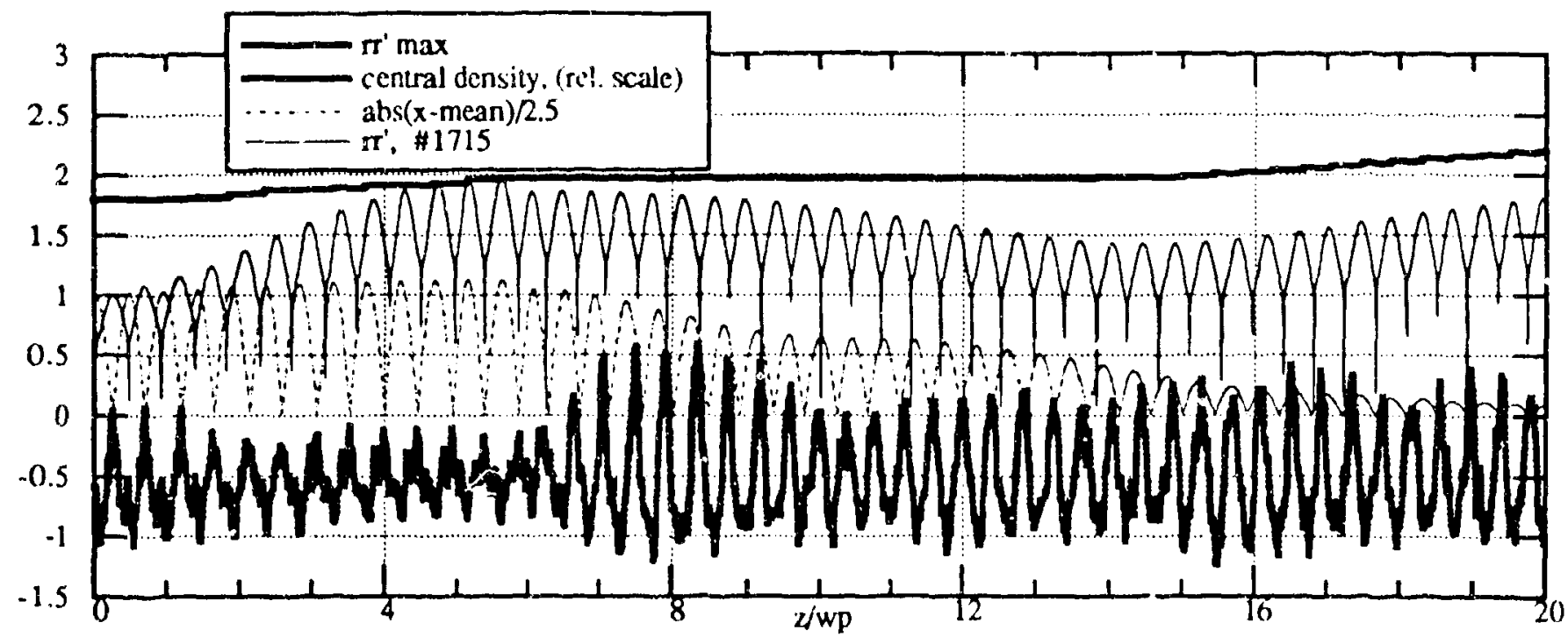

Fig. 7. Hamiltonian $\sigma / \sigma_{0}=0.83$ distribution misaligned $50 \%$ of beam radius in $x$.

\section{SUMMARY}

Beller knowledge of how halos are actually formed gives specific rationale for modeling descriptions of total beam behavior, development of space-charge tune architecture, and scaling/optimization procedures. In future work, it is of interest to explore the falures (e.g., the relative growth of core vs. halo, limiting behavior, adddition of multiple errors) of each type of perturbation, plus others such as aliernating gradient focusing, constant-beta scetions of accelerator cells, and graded-beta aceeleration - all sources of time-dependent behavior. There are many practical aspects, e.g., tune strategy regarding misalignment, deterrianation of adrquate apxerture faclors, and error tolerances, that need to be worked out. P. Channell has begun theoretical modeling of the core/singleparticle interactions, and $R$. Gluckstem has sketched a molel for the resonance crossing with self-limiting behavior. We must tir these together, Jescritie the tune spread of beams under various conditions, and relate the tunc spread to the various resonances and number of particles that will $1 x$ : exa. We hope to use this new insight into the actual haio growth mathanism to axcomplish macro-menteling of the total lx:am size.

\section{ACKNOWLIEDGMIENTS}

The able assistance of (i. Hoicoun with the simulations is pratefully acknowledged, as are discussinus will P'. (hannell and R. Giluckstern, who are now working on the theory, and uher discoussions will T. Wangle's and ('. Mohn.

\section{RIIIIRIENCIS}

11) (1) Howman, II) Arthur, el. Al. "Nuclear Inetgy

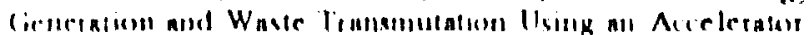

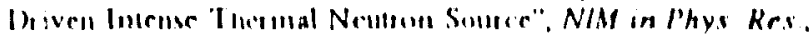

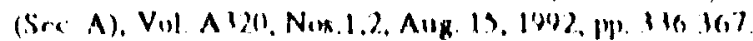

[2] F. Venneri, C. Bowman, R. Jameson, "Accelerator-Driven Transmutation of Waste (ATW) - A New Method for Reducing the Long-Term Radioactivity of Conmercial Nuclear Waste". LA-UR-93-752. Los Alamos Natl. Lab.. sub. for publ. to Physics World, Bristol, England.

[3] A. Jason, et. al., "Los Alamos Design Study for a High Power Spallation Neutron Source Driver", these procedings.

[4] "Accelerntor Production of Tritium", JASON Report JSR 92 310, The Miue Corporation, Mclean, VA (1992).

[5] R.A. Jameson. "Accelerator-Driven Neutson Sou es for Materials Research". NIM in Phys. Res. B56/57 (1991) 982. 986.

[6] R.A. Jameson, "Or Scaling \&. Optimization of High Intensity, Low Heam L ass RF Linecs for Neutron Suurce Drivers". LA UR 92 2474. I As Alamos Nall. Lab., Pros 3rd Workshop on Adv. Aicel Consepts, 14.20 June 1942. Pont Jefferson, Long Island, NY, American Institute of Physics.

[7] J. Hofmann, I. Hozsik, "Compute: Simulation of Longitudinal Transverse Space Charge Effects in Bunched Beams", 1981 Lirua Conf. L.A 9234.C. Ios Nlamos, Natl. lab., pp.116.119.

(k) R.A. Jameson. "Benm Intersity limilations in Linenr Acreleralers". IEEE Trans Nucl, Sri. Vol. NS 28, Ne. I, June 1481, pm. 2A1)8 2412 .

191 R.A. Jameson, "Equipartitionalug in h.inear Accolerators", 1081

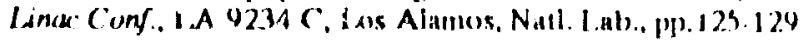

[10) T.P. Wangler, ot. al., "Kelation IBetween Field Energy nul KMS Emillance in Intense Particle Beans", 1985 PAC, II 21 Trams. Nucl. Sci., Vol. NS 32. No. S. (kelolier luss.

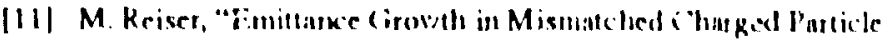

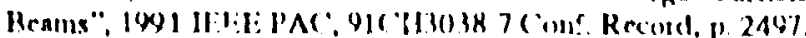

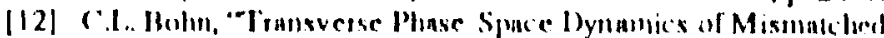

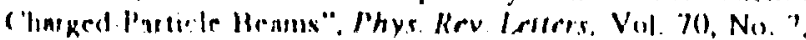
15 lirb. $1903,0.432$

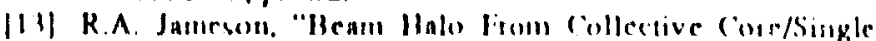

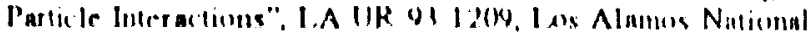
Inlournlory. March lops

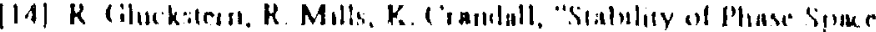

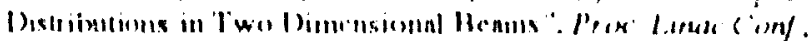

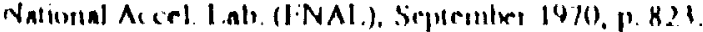

